\title{
Conversação, telejornalismo, democracia e a retórica da participação do público.
}

\section{Fernanda Mauricio Silva}

\section{Resumo}

0 presente artigo tem como objetivo discutir os modos de participação dos telespectadores nas conversações encenadas no telejornalismo, a fim de problematizar seu papel democrático. Através da análise do programa Roda Viva (TV Cultura), observa-se que o telejornalismo emprega três níveis de inclusão do público em seus programas: pleno, oculto e representativo. Procurase demonstrar, a partir da contribuição dos cultural studies, que 0 telejornalismo ainda se apresenta de maneira autoritária e excludente com relação à inserção do público nas conversas postas em cena.

\section{Palavras-chave:}

Conversação. Telejornalismo. Democracia. Participação.

Fernanda Mauricio Silva I fernandamauricio@gmail.com Doutora em Comunicação e Cultura Contemporâneas pela Faculdade de Comunicação da Universidade Federal da Bahia (UFBA). Bolsista de pósdoutorado na UFBA.

\section{Introdução}

Nas teorias democráticas mais recentes, 0 cidadão possui um lugar central no agenciamento político. Tanto na perspectiva republicana, quanto para o deliberacionismo, a conversação desponta como prática por excelência para a expressão da vontade e da opinião públicas, através do debate livre e igualitário entre os cidadãos, debate este que se baseia em apenas dois critérios: a razão e 0 argumento. Sendo assim, para além da ação política por meio do voto, os cidadãos poderiam participar da democracia através da troca de ideias, da deliberação e da prática argumentativa que, segundo tais perspectivas, ajudam a formar um cidadão politicamente mais atuante.

Na formação do discurso democrático, a imprensa consolidou-se como instituição mediadora entre o público e as decisões políticas. Se olharmos para a história do jornalismo, encontraremos nos jornais impressos do século XIX - período em que as práticas democráticas tornavam-se recorrentes em países como Inglaterra e Estados Unidos - um espaço para que os leitores manifestassem sua 
opinião sobre os assuntos que diziam respeito ao seu papel como cidadãos (BRAGA, 2006b, p. 134). Assim, o próprio jornalismo pretendia constituir-se como uma arena aberta para os cidadãos igualitários expressarem-se livremente. Com a formulação do conceito de esfera pública por Jürgen Habermas (1984), a relação entre democracia, debate público e mídia ganhou ainda mais relevo e, apesar das críticas do autor sobre 0 papel alienante dos meios massivos, o jornalismo, independentemente do suporte, ainda sustenta seu papel social sobre o fomento da discussão e da formação da opinião pública.

Esta é a principal motivação para a existência de programas televisivos dedicados ao debate entre representantes das esferas política, econômica e cultural. Quando surgiram as primeiras televisões públicas da Inglaterra (com a BBC) e França (com a RTF), boa parte da programação era dedicada a programas de entrevistas e debates que buscavam cumprir o papel de educar e informar (SEATON, 2003; COHEN, 1999). No Brasil, foi no processo de redemocratização, no início dos anos 1980, que programas de debate e entrevista se multiplicaram na grade de programação de TVs comerciais e públicas. 0 uso da conversação como estratégia buscava inserir na discussão jornalistas, representantes da cena pública e telespectadores, convocando o sentido de participação tão caro para a teoria democrática.
0 presente artigo tem como objetivo compreender a relação entre telejornalismo, conversação e democracia através das estratégias de inclusão da audiência no debate proposto pelo programa Roda Viva, da TV Cultura. Esse recorte deve-se não apenas à longevidade e prestígio ${ }^{1}$ do programa, mas à afirmação de um compromisso com "[...] o debate democrático e reflexivo em torno de temas e idéias" (RODA VIVA, 2011). Assim, 0 programa apresenta-se como um profícuo lugar de análise das possíveis formas de participação empregadas em programas jornalísticos que usam a conversação como fundamento para sua relação com a audiência.

0 artigo parte de uma consideração geral sobre a relação entre conversação, jornalismo e democracia para as mais recentes teorias políticas, em especial a perspectiva republicana e 0 deliberacionismo, nos quais as noções de participação, cidadania e conversação parecem possuir um lugar central. Em contrapartida, pretendemos trazer uma contribuição dos cultural studies ao conceito de esfera pública, a fim de demonstrar os limites da formulação habermasiana para a democracia. Em seguida, discutimos os modos como o público é incluído nas práticas conversacionais do Roda Viva a partir três níveis de envolvimento: 0 nível pleno, quando a pessoa aparece e participa; o nível oculto, quando aparece, mas não participa; $\mathrm{e}$ o nível representativo, quando não aparece, 
mas participa. A conclusão demonstra que 0 telejornalismo ainda se apresenta de maneira autoritária e excludente com relação à inserção do público nas conversas postas em cena.

\section{As perspectivas sobre a relação entre jornalismo, conversação e democracia}

0 papel político desempenhado pelo público ocupa um lugar central nas formulações mais clássicas da teoria democrática (TARDE, 1992; BLUMER, 1971; HABERMAS, 1984). É a partir da vontade, do interesse e da opinião do público que os governos democráticos procuram orientar suas ações. No entanto, no desenvolvimento da democracia, algumas perspectivas adotaram diferentes concepções sobre o papel cívico do público. No liberalismo clássico (e na versão neo-liberal), o cidadão possui plena autonomia e liberdade para tomar decisões racionais em busca de sua felicidade. Dialogando com uma perspectiva iluminista sobre a identidade, notase que de acordo com a perspectiva liberal, 0 indivíduo é autocentrado, completo e plenamente formado, capaz de expressar sua opinião e exercer seu papel político de forma quase espontânea (DAHLGREN, 2006). Uma perspectiva contrária, a do "comunitarismo", prega a existência de uma comunidade pré-política para que a democracia funcione adequadamente. É nessa comunidade que 0 indivíduo exercitaria seu papel cívico e aperfeiçoaria a cidadania.

Nos anos 1990, uma nova perspectiva sobre a cidadania ganhou força na formação do discurso democrático. 0 modelo republicano põe ênfase especial nos direitos individuais, no entanto estes devem ser negociados no interior e nas práticas de uma comunidade, associação ou grupo social. Deste modelo, duas noções emergem como centrais para o exercício do papel político individual: a participação, que expressa 0 caráter ativo do cidadão e seu envolvimento na vida pública, e a sociedade civil, que oferece uma espécie de iniciação dos indivíduos na vida política, uma vez que, por meio das interações dos indivíduos associados, eles podem adquirir competência cívica e fortalecer a democracia.

Tal perspectiva encontra no conceito habermasiano de esfera pública um lugar para 0 desenvolvimento do agenciamento político. Para Habermas (1984), era na esfera pública burguesa (encontrada pelo autor na sociedade inglesa do século XVIII) que os indivíduos privados se transformavam num público. Nesse fórum público de debates, os indivíduos possuíam apenas duas armas: 0 argumento e a discursividade. Assim, era por meio das conversações que argumentos racionais eram formulados e trocados de modo a efetuar a deliberação. 0 conceito de esfera pública está estritamente ligado à formação do Estado moderno iluminista, uma vez que era pelo exercício da ratio que todos os indivíduos poderiam ter acesso ao debate público. A finalidade última era a formação da opinião pública, um conjunto de vontades consensuais, obtido por meio do debate argumentativo racional. 
Deste modo, a discussão, argumentação e interação possuem um lugar significativo na prática democrática. A própria definição de esfera pública traz a igualdade e a conversação como princípios fundamentais para sua formação:

[esfera pública é] 0 domínio da nossa vida social no qual algo próximo à opinião pública pode ser formado. 0 acesso é garantido a todos os cidadãos. Uma porção da esfera pública vem a existir em cada conversação na qual cada indivíduo privado agrupa-se para formar um corpo público (HABERMAS, 1974, p. 49).

Para Habermas (1984), o argumento era a

credencial para o engajamento nos diálogos, de modo que qualquer cidadão, independentemente de classe, faixa etária, poderia interagir. Na relação entre "democracia" e "conversação", "igualdade" é um referente constantemente empregado como propriedade essencial para que as duas instâncias se efetuem de maneira saudável. Assim, o exercício da democracia deveria estar enraizado na livre participação de indivíduos igualitários que, por meio do argumento e do debate público, tomam decisões e são capazes de agir politicamente. Tais perspectivas esbarram, porém, no sistema de governo escolhido: a representação, ao invés da livre participação, confinou a personalidades e espaços distintos o dever de debater e tomar decisões. Como ressalta Wilson Gomes (2005, p. 216),

[...] a consolidação da experiência democrática moderna, principalmente através dos modelos de democracia representativa, findou, entretanto, por configurar uma esfera da decisão política apartada da sociedade ou esfera civil. 0 âmbi- to da decisão política é constituído, então, por agentes em dedicação profissional e por membros de corporações dedicadas ao controle e distribuição do capital circulante nesta esfera - os partidos -, dotando-se de altíssimo grau de autonomia em face da esfera civil. Constitucionalmente, as duas esferas precisam interagir apenas no momento da renovação dos mandatos, restringindo-se o papel dos mandantes civis à decisão, de tempos em tempos, sobre quem integrará a esfera que toma as decisões propriamente políticas.

Como consequência dessa separação entre a esfera civil e as instâncias de tomada de decisão, a participação tornou-se algo pouco tangível, apesar de ainda estar no cerne do pensamento democrático. Wilson Gomes (2005) afirma que a dimensão de participação precisa existir, ainda que retoricamente, para que o governo atue a partir de um direcionamento da opinião pública. Por conta disso, novas perspectivas sobre a democracia procuram inserir no modelo democrático representativo níveis de participação que, ainda que não atuem diretamente na tomada de decisões, podem reforçar valores democráticos mais amplos.

0 deliberacionismo surgiu nos anos 1990 como oposição às tradicionais correntes de pensamento sobre a comunicação e a política a tradição liberal e a republicana - colocando no centro do debate a formação de uma arena discursiva entre o Estado e a sociedade, arena esta que seria a própria esfera pública forte e atuante. Assim, as tomadas de decisão ocorridas periodicamente nas eleições não são suficientes para assegurar a democracia, que deve estender- 
se para a conversação cotidiana, que permite maior reflexão sobre os problemas sociais. Para os autores afiliados a essa perspectiva, deliberar não é apenas 0 ato de tomar decisões, o que afastaria boa parte da sociedade dos processos democráticos, como explicou Gomes (2005), mas envolve todo o processo argumentativo e 0 "[...] intercâmbio de razões feito em público" (MAIA, 2008a, p. 166).

Nesse contexto, a conversação informal cotidiana é um forte elemento para a concretização da democracia. Tomando a política num sentido mais amplo, que não se limita às questões que estão no centro do poder, mas estende-se aos contextos práticos da vida cotidiana e às configurações da sociedade civil, os deliberacionistas afirmam que

[...] a conversação cotidiana também é fundamental para a vitalidade da democracia, já que ela provê tópicos e configura valores para serem defendidos na esfera pública e, ainda, prepara os cidadãos para que se engajem em trocas argumentativas exigentes (MAIA, 2008b, p. 203).

Independentemente da perspectiva adotada, é possível notar que a relação entre jornalismo, conversação e democracia se dá no âmbito da influência de um sobre 0 outro na vida cotidiana. A formação da opinião e o caráter democrático da conversação, nesses estudos, expressam-se e ganham valor nas interações sociais ordinárias. Como afirma Gabriel Tarde (1992, p. 136), em seu clássico trabalho sobre a opinião e as massas, "[...] politicamente, não são tanto as conversações e discussões parlamentares, e sim as conversações e discussões privadas, que importa considerar". Sendo assim, a dimensão democrática da conversação ocorre na vida cotidiana e não no âmbito da comunicação de massa. A formação de uma esfera pública forte e ativa se dá pela ação da mídia, mas não a tem como palco para a fomentação das conversações políticas relevantes entre indivíduos comuns.

\section{Democracia, mass media e conversação na perspectiva dos cultural studies}

Um dos principais críticos contemporâneos do conceito habermasiano de esfera pública é Peter Dahlgren (2006). Segundo ele, a valorização do público (que traz os ideais de razão, argumentação, objetividade, informação, conhecimento) em detrimento do privado (que remete ao pessoal, sensível, prazer, entretenimento) não permite conhecer as motivações, identidades e paixões que levam os indivíduos ao debate público. Por isso, Dahlgren (2006) não pretende contestar o conceito de esfera pública, mas oferecer uma perspectiva mais empírica (menos normativa), que explique as dinâmicas entre a vida cotidiana e a sociedade civil, entre a formação das identidades no âmbito privado e o engajamento dos sujeitos na vida política.

Pensando numa articulação entre a formação de uma esfera pública plural e o papel da televisão, Sonia Livingstone e Peter Lunt (1994) afirmam que os meios massivos, ao darem visibilidade 
a assuntos e pessoas que pouco participam do circuito midiático, permitem 0 ingresso dos temas privados e do sensível, constituindo uma esfera pública alternativa. A perspectiva adotada pelos autores, portanto, amplia a dimensão postulada por Jürgen Habermas e pelas teorias políticas que dela derivam, sobretudo no que tange ao papel dos meios de comunicação na construção da esfera pública, na concepção de "público" e nas distinções entre o público e o privado. Para Livingstone e Lunt (1994), as relações entre media, poder e sociedade são explicadas pelas possibilidades de tensão que os públicos podem oferecer na cultura. A televisão, portanto, se apresenta não como veículo reducionista dos papeis políticos que os indivíduos podem exercer na democracia, mas como forma de "facilitar e legitimar a negociação pública - através do compromisso e não do consenso - dos significados entre os grupos oposicionais e marginalizados" (LIVINGSTONE; LUNT, 1994, p. 10-11).

As observações de Livingstone e Lunt (1994) estão orientadas para o que eles denominam como "programa de participação da audiência" (audience participation programmes), um tipo específico de talk show que leva para o estúdio pessoas comuns para falarem sobre problemas que normalmente não são pautados pela mídia tradicional - problemas familiares, distúrbios psíquicos - ou vitórias sobre os desafios da vida cotidiana - doenças, desemprego, vícios. 0 conhecimento especializado, que sempre marcou os debates públicos efetuados pelos media até os anos 1990, cede lugar ao conhecimento leigo que se constrói pela experiência vivida e partilhada com a audiência. A presença da plateia no estúdio assegura ainda mais o lugar que esses programas pretendem construir para si: um locus onde as questões vividas e sentidas pelo telespectador ganham relevância e dúvidas podem ser esclarecidas ao vivo.

\section{Níveis de participação da audiência na conversação do Roda Viva}

É em função dessa tentativa de cumprir seu papel político que os programas que tomam a conversação como marca de sua construção e relação com a audiência procuram inserir os telespectadores. Tomamos como recorte para a discussão proposta neste artigo o programa Roda Viva, exibido pela TV Cultura, no período de 2006 a $2010,{ }^{2}$ uma vez que as possibilidades de inserção da audiência no debate televisivo constitui-se como uma das matrizes principais da identidade do programa desde seu surgimento, em $1986 .^{3}$ A análise aqui apresentada levou em conta os

Em agosto de 2010, o Roda Viva passou por diversas reformulações: a exibição passou a ser gravada, a reformulação do cenário colocou o entrevistado no mesmo patamar dos entrevistadores, entrevistadores fixos passaram a dividir a bancada com apresentadora. Como o programa deixou de ser ao vivo, as observações do público deixaram de fazer parte do programa, por isso as edições recentes do Roda Viva não foram consideradas neste artigo.

Uma discussão mais específica sobre as estratégias do Roda Viva para a construir-se como uma arena de debates encontra-se em Silva (2010). 
critérios estabelecidos por José Luiz Braga (1994) para a investigação da conversação televisiva: vez de falar; movimentos para início e fim da troca, e duração global; os papéis e as relações entre os participantes; quadros, territórios e meios; graus de formalização, controles e institucionalização; objetivos e resultados; assuntos, temas e matérias; número de participantes e possibilidade de participar.

Há 25 anos, o Roda Viva traz como atributo a possibilidade de interação dos telespectadores com os entrevistados de cada edição. Como ressalta a matéria publicada na revista Veja no período de sua estreia,

'Muitas vezes as melhores perguntas são dos telespectadores', diz Gamberini [primeiro apresentador do programa]. Na entrevista de Meneguelli [presidente da Central Única dos Trabalhadores], por meio de uma centena de telefonemas, o público queria saber coisas bem mais concretas - se 0 sindicalista trabalhava, qual o seu salário, quem pagou suas viagens a Cuba e à União Soviética -, enquanto a bancada de entrevistadores fazia perguntas sobre a Assembléia Constituinte e a dívida externa brasileira (DEBATE VIV0, 1987, p. 113).

0 Roda Viva foi ao ar pela primeira vez num momento de investimento das emissoras no telejornalismo. Num período em que a sociedade e a política se abriam para o debate livre de ideias, a TV Cultura lançou o Roda Viva a fim de incorporar as novas relações sociais e um modelo de conversação baseado na contradição e troca de argumentos. Com um cenário que reproduz uma arena, o Roda Viva se configura num espaço em que as entrevistas darão subsídios para fomentar um debate sobre os assuntos. No centro, encontra-se 0 entrevistado que se submete a uma sabatina de perguntas pelos entrevistadores convidados, posicionados numa plataforma um nível acima. A conversa é iniciada pelo mediador principal e a palavra é, logo, passada aos demais entrevistadores - um grupo formado por jornalistas de diversos veículos de comunicação, representantes de instituições, intelectuais que tenham alguma relação com o convidado - que criam formas próprias para entrar na conversa: interrupções e sobreposições são frequentes na passagem da palavra de um falante a outro.

0 convidado do Roda Viva, geralmente alguém de destaque no cenário político, econômico, cultural, esportivo, midiático, está em constante posição de defesa (de ideias, de planos de governo etc). É nesse inquérito que o programa cumpre seu pacto sobre o papel do jornalismo: um vigilante dos poderes públicos e da sociedade. Por isso, o programa esforça-se para incluir os telespectadores, como se estivesse na mesma condição dos demais participantes da troca.

A participação do público é tão relevante para 0 debate proposto que quando a edição é gravada, 0 apresentador salienta que os telespectadores não podem participar diretamente. No entanto, o programa busca não perder o contato com a audiência: "0 programa de hoje está sendo gravado e, portanto, não permite a participação direta do telespectador. Mas você pode mandar a 
sua crítica, sua sugestão, sua proposta, pelo site do programa..." (Paulo Markun, 21 ago. 2006).

A partir da construção do debate na arena do Roda Viva, observamos que o telejornalismo procura incluir a pessoa comum na conversação de três maneiras: primeiro, de forma evidente, quando o público aparece na conversa e participa (nível pleno); segundo, quando aparece, mas não participa (nível oculto); terceiro, quando não aparece, mas participa (nível representativo). ${ }^{4}$

No nível pleno, a própria pessoa aparece no televisor dirigindo sua pergunta ou comentário ao convidado e aos demais participantes da conversação. Essa forma representa a inclusão do público na cena do programa, dando-lhe 0 direito à palavra, o que reforçaria plenamente os ideais democráticos. 0 público, nesse caso pode aparecer ao vivo no programa como convidado, como parte de uma plateia, ou num VT gravado. No período analisado, a entrevista com a então candidata à presidência da república Heloísa Helena (12 jun. 2006) trouxe cinco representantes do público: uma professora, um líder comunitário, um estudante, um taxista e uma esteticista, todos identificados pelo nome e profissão. Essas pessoas apareceram no programa por meio de um VT feito anteriormente à exibição do Roda Viva, o que demonstra um preparo prévio da equipe de produção do programa. Também evidencia a tentativa de agrupar as perguntas das pessoas comuns e inseri-las no programa num momento em que os assuntos tratados apareçam durante a conversa, como ressalta 0 apresentador: "já que estamos falando com uma socialista, eu queria encerrar o programa com duas perguntas de telespectadores curiosos a respeito da sua forma de ser, do seu comportamento e marca pessoal, vamos lá"; "senadora, a respeito das manifestações e das reivindicações dos trabalhadores sem-terra, nós temos aqui as perguntas de duas pessoas ouvidas pelo Roda Viva em São Paulo. Vamos ver" (Paulo Markun, 12 jun. 2006). As perguntas dirigidas pelo público buscam obter informações, mas também confrontam os participantes no estúdio para um posicionamento claro sobre suas posições como governante: "Senadora Heloísa Helena, diante da gravidade dos fatos da semana passada, ou seja, da invasão dos sem-terra na Câmara dos Deputados [invasão promovida pelo Movimento pela Libertação dos Sem Terra em junho de 2006. 497 integrantes do movimento foram presos e 41 pessoas ficaram feridas], o que a senhora, como presidente, faria?", "Pergunto o seguinte, no seu governo haverá reforma agrária?", "Você que tem gênio tão forte, está se candidatando à presidência do Brasil, o que você vai fazer pela gente com esse gênio todo que você tem?". As respostas a essas perguntas são um dos 
poucos momentos em que a convidada olha para a câmera, reforçando o caráter dialógico que pretende manter com o público, que logo se dispersa após a introdução de uma nova pergunta formulada por um dos entrevistadores no estúdio.

Embora permita que a própria pessoa formule sua pergunta ao entrevistado, o Roda Viva concede um espaço reduzido no acesso à conversação, uma vez que a troca se dá num único turno de fala. Não há possibilidade de retrucar a resposta, reivindicar uma explicação mais ampla, discordar, complementar a pergunta e promover 0 debate que 0 programa busca assegurar. Assim, a estratégia plena, no Roda Viva, aparece mais como uma estratégia retórica do programa para fazer uma cena de debate público do que uma estratégia que efetivamente permite 0 acesso igualitário aos demais participantes na troca. Na construção da deliberação, os argumentos do público participante da conversação não são formulados e defendidos em cena.

0 nível oculto permite que o público assista à conversa in loco, mas não lhe é permitido 0 direito à palavra. A pessoa comum aparece geralmente numa plateia - mas não possui voz, servindo apenas como espectadora dos diálogos ali travados, ausente da conversação. Até 2008, 0 Roda Viva tinha uma plateia, situada no segundo andar da arquibancada, que assistia à cena, interagia com os convidados nos intervalos do programa, tomava nota dos assuntos tratados, mas não possuía acesso à conversação, não era permitido fazer perguntas ou comentários.

Em 2008, porém, o programa mudou as formas de transmissão e de recepção, reconfigurando 0 envolvimento da audiência. A plateia podia partilhar suas impressões pela internet com outros "seguidores" do Roda Viva no Twitter. Assim, o programa convocou um sentido de participação que se afasta da "passividade" de uma plateia que apenas ouve, mas que pode partilhar com outros suas impressões sobre 0 programa indicando seu nível de participação, ainda que numa esfera extra cena televisiva.

A forma representativa é a maneira mais comum pela qual os programas televisivos permitem 0 acesso do público à conversação. Nesse modelo, os telespectadores participam através do envio de perguntas e comentários por e-mail, fax ou telefonema, respondendo a enquetes que são comentadas durante a emissão do programa. Sua voz é representada por um jornalista da emissora responsável por selecionar as perguntas que devem ir ao ar e lê-las ao vivo.

0 Roda Viva, no período analisado, ofereceu um rodízio de jornalistas que cumpriam esse papel, o que não permitiu a construção de familiaridade entre os telespectadores e seu representante na cena do programa. Para inserir as perguntas dos telespectadores no programa, a jornalista que os representa buscou manter a fluidez das conversas, aproveitando as "deixas" de outros entrevistadores para incluir as questões levantadas pelo público: 
"E por falar em Rodelas, a gente já tem a pergunta de um dos telespectadores [...]" (ao ator Wagner Moura, 29 set. 2008). Fora os momentos em que inseria as falas dos telespectadores, a mediadora não possuía lugar nas trocas do programa, excluindo-se de uma participação mais efetiva nos momentos de debate.

Esse distanciamento entre 0 telespectador e a conversa em cena, além da redução de sua participação a apenas um turno de fala (pergunta/ resposta), põe em questão o caráter igualitário dos participantes da conversação, tomado como natural entre os autores da teoria democrática. Michael Schudson (1997) contesta o princípio de igualdade, uma vez que não há nada na natureza da conversação que sugira isso. Os autores que abordam e/ou analisam a conversação - Goffman (1986), Sacks (1979), Burke (1995), Tarde (1992), Grice (1979) - afirmam a necessidade de uma competência cultural adquirida para participarem das trocas cotidianas. Se essa partilha de um background precisa existir para que a conversação se efetive, é necessário pensar, de acordo com Schudson (1997), sobre quem está incluído e quem não está, quem é efetivamente membro da conversação na democracia e quem está excluído. Peter Burke (1995) destaca as clivagens hierárquicas que marcaram as conversações ao longo da história, determinando certos usos da linguagem por parte de empregados em relação aos seus patrões, mulheres em relação aos homens etc. Assim, a igualdade entre os indivíduos na conversação cotidiana, tomada como princípio regulador das trocas, aplicava-se apenas aos grupos específicos sobre os quais se falava e não para toda a sociedade.

Para Schudson (1997), a atenção deve estar nas regras que tornam a conversação homogênea ou pluralista. A democracia, segundo o autor, deveria caracterizar-se mais pela heterogeneidade do que pela igualdade. Levando-se em conta a disseminação de diferentes estilos de vida na cultura pós-moderna, a dimensão de igualdade deve ser revista para pensar a multiculturalidade. Assim, Schudson defende que é na heterogeneidade, antes da igualdade, que a conversação na democracia adquire seu caráter público, permitindo reconhecer as tensões que envolvem a democracia e a verdadeira promoção do debate público. Schudson (1997, p. 307) conclui, portanto, que

[...] 0 que faz a conversação na democracia não é a livre, igualitária e espontânea expressão, mas 0 acesso igualitário ao palco, a participação igualitária no estabelecimento das regras básicas para a discussão, e um conjunto de regras desenhadas para encorajar a fala pertinente, a escuta atenta, as simplificações apropriadas e a ampla porção de direitos de falar.

0 telejornalismo privilegia o lugar dos pares na construção da conversação. Apesar de abrirse a pontos de vista distintos, a competência comunicativa deve ser comum aos interlocutores, o que impossibilita a participação da pessoa comum in loco, propondo suas temáticas a partir de seu estilo de vida. 0s representantes eleitos para dar voz à audiência do interior do programa 
precisam ser credenciados pelo campo jornalístico e não pelas próprias representações do público nas práticas culturais cotidianas.

\section{Considerações finais}

0 potencial político da conversação na vida cotidiana e as possibilidades de participação dos "públicos fracos" (MAIA, 2008a) - pessoas que estão excluídas do centro de tomada de decisões -, apontam para uma assimetria entre as gramáticas midiáticas de comunicação e a habilidade desses púbicos na interação. A ausência de um vocabulário específico, por exemplo, impede a inserção da pessoa comum nos debates televisivos.

Por conta disso é que a representação aparece de forma tão naturalizada nos meios de comunicação. É notável o esforço dos programas em convocar a participação da audiência, especialmente com 0 uso de recursos digitais. No entanto, ainda não é a própria pessoa comum que aparece ao lado dos jornalistas e dos convidados expondo-se e oferecendo seus argumentos. Do ponto de vista da construção de uma conversação democrática e das possibilidades de participação, a abordagem representativa reproduz o modelo de democracia representativa: há alguém que interage no lugar do público. 0 público delega aos jornalistas as possibilidades expressivas para que ele, que detém o controle da situação comunicativa, insira suas opiniões no momento adequado, de modo a fazer sentido durante a conversa.
Na construção da gramática da conversação televisiva, especialmente quando esta se apresenta mais argumentativa, o que a tradição seletiva do telejornalismo demonstra é a construção de uma autoridade baseada tanto no domínio de uma linguagem específica que vincula os participantes ao campo político, quanto a compreensão de assuntos que se ligam mais à máquina de governo do que ao que é vivido pela audiência, o que invalida a presença de representantes do público na conversação. As proposições democráticas se relacionam mais com uma construção do que deveria ser a conversação nos programas que se vinculam ao modelo dominante do jornalismo, do que propriamente com a falta de habilidade de público em formular ideias. Assim, os limites de participação da audiência não podem ser vistos como uma falta de interesse cívico, mas um constrangimento trazido pelos meios de comunicação aos modos de conversar sobre política das pessoas comuns, que estariam desvinculados dos critérios televisivos.

Como a conversação é tomada nos programas em seu sentido mais iluminista, a necessidade de uma argumentação baseada na racionalidade (e não no sensível) e nos assuntos públicos (e não privados) torna a participação do público restrita a momentos específicos e controlados pelos agentes do campo jornalístico. Por conta disso, a proposta de promoção de um debate público, embora se cumpra na vida cotidiana, não encontra espaço na cena televisiva do telejornalismo. 


\section{Referências}

BLUMER, Herbert. A massa, o público e a opinião pública. In: COHEN, Gabriel (Org.). Comunicação e indústria cultural. São Paulo: Companhia Editora Nacional, 1971, p. 177-186.

BRAGA, José Luiz. Roda Vida: uma encenação da esfera pública. In: ENCONTRO ANUAL DE NÚCLEOS DE PESQUISA DA INTERCOM. 2006, Brasília. Anais... Brasília: INTERCOM, 2006a.

BRAGA, José Luiz. A sociedade enfrenta a sua mídia: dispositivos sociais de crítica midiática. São Paulo: Paulus, 2006b.

BRAGA, José Luiz. Sobre a conversação. In: FAUSTO NETO, Antonio, Sérgio Dayrell Porto; BRAGA, José Luiz (Org.). Brasil: comunicação, cultura e política. Rio de Janeiro: Diadorim, 1994. p. 289-308.

BURKE, Peter. A arte da conversação. São Paulo: Editora da Unesp, 1995.

COHEN, Évelyne. La télévision dans les démocraties annés 30- annés 80. In : FRÉCHET, Hélène (Coord.). La démocratie aux ÉtatsUnits et en Europe 1918-1989. Paris: Editions du Temps, 1999. p. 211-229.

DAHLGREN, Peter. Doing citizenship: the cultural origins of civic agency in the public sphere.

European Journal of Cultural Studies, London, v. 9 , n. 3 , p. 267-286, 2006.

DEBATE vivo. Inovações nas entrevistas do programa Roda Viva. Veja, São Paulo, n. 964, fev. 1987.

GOFFMAN, Erving. Frame Analysis: an essay on the organization of experience. Boston, Northeastern University Press, 1986. 577 p.

GOMES, Wilson; MAIA, Rousiley. Prefácio. In: Comunicação e democracia: problemas e perspectivas. São Paulo: Paulus, 2008. p. 11-27. GOMES, Wilson. Internet e participação política. In: GOMES, Wilson; MAIA, Rousiley. Comunicação e democracia: problemas e perspectivas. São Paulo: Paulus, 2008. p. 293-325.

GOMES, Wilson. A democracia digital e o problema da participação civil na decisão política. Revista Fronteiras - estudos midiáticos, v. VII, n. 3, p. 214-222, set./ dez. 2005.

GRICE, Paul H. Logique et conversation.

Communicatios, Paris, n. 30, 1979, p. 57-72.

HABERMAS, Jürgen; LENNOX, Sara; LENNOX, Frank. The public sphere: an Encyclopedia Article (1964). New German Critique, Durham, n. 3, p. 49-55, 1974. Disponível em http://links.jstor.org/ sici?sici=0094-033X\%28197423\%290\%3A3\%3C 49\%3ATPSAEA\%3E2.0.C0\%3B2-Z, acesso em 20 nov. 2009 .

HABERMAS, Jürgen. Mudança estrutural da esfera pública: investigações quanto a uma categoria da sociedade burguesa. Rio de Janeiro: Tempo Brasileiro, 1984. 
LIVINGSTONE, Sonia M.; LUNT, Peter. Talk on

television: audience participation and public

debate. London and New York: Routledge, 1994.

MAIA, Rousiley. Visibilidade midiática e

deliberação pública. In: GOMES, Wilson;

MAIA, Rousiley. Comunicação e democracia:

problemas e perspectivas. São Paulo: Paulus, 2008a. p. 165-194.

MAIA, Rousiley. Conversação cotidiana e deliberação. In: GOMES, Wilson; MAIA, Rousiley.

Comunicação e democracia: problemas e

perspectivas. São Paulo: Paulus, 2008b. p. 195-219.

MAIA, Rousiley; MARQUES, Angela. A conversação sobre temas políticos em contextos comunicativos do cotidiano. Política \& Sociedade, n. 12, p. 143175. abr. 2008.

MAIA, Rousiley; MARQUES, Angela; MENDONÇA, Ricardo. 0 sistema deliberativo e seus espaços discursivos: a articulação entre diferentes modos de comunicação. ENCONTRO DA COMPÓS, 16., 2007, Curitiba. Anais... Curitiba: COMPÓS, 2007. Disponível em: < http://www.compos.org.br/data/ biblioteca_135.pdf>. Acesso em: 23 dez. 2009.

MONTAIGNE, Michel. Da arte de conversar. In: . Ensaios 52. Rio de Janeiro, Porto Alegre, São Paulo: Editora Globo, 1961. p. 224-239.

ÖRNEBRING, Henrik; JÖNSSON, Anna Maria. Tabloid journalism and the public Sphere. Journalism Studies, v. 5, n. 3, p. 283-295, Aug. 2004.
ÖRNEBRING, Henrik. Televising the Public

Sphere. Forty years of current affairs debate programmes on Swedish television. European Journal of Communication, v. 18, n. 4, p. 501$527,2003$.

REZENDE, Guilherme Jorge de. Telejornalismo no Brasil. Um perfil editorial. São Paulo: Summus, 2000.

RODA VIVA. Sobre o Roda Viva. Disponível em: < http://www.tvcultura.com.br/rodaviva/oprograma > . Acesso em: 11 jul. 2011.

SACKS, Harvey. Lectures on conversation.

Oxford: T.J. Press, 1979.

SCHUDSON, Michael. Question of authority: a history of the news interview. The Power of News. Cambrige, Londres: Harvard University Press, 2003b. p.72-93.

SCHUDSON, Michael. Why conversation is not the soul of democracy. Critical Studies in

Mass Communication, v. 14, p. 297-309, 1997.

Disponível em: < http://verbalperambulation.files. wordpress.com/2007/02/schudson-michael-whyconversation-is-not-the-soul-of-democracy.pdf $>$. Acesso em: 31 mar. 2009.

SEATON, Jean. Broadcasting history. In: CURRAN, James; SEANTON, Jean. Power without responsibility: the press, broadcasting and new media in Britain. 6.ed. London; New York: Routledge, 2003. 107-234. 
como estratégia de construção de programas

jornalísticos televisivos. 2010. 294f. Tese

(Doutorado em Comunicação) - Programa de

Pós-graduação em Comunicação e Cultura

Contemporânea, Universidade Federal da

Bahia, Salvador, 2010. Disponível em: < http://

telejornalismo.org/wp-content/uploads/2010/05/

SILVA-Fernanda.-A-conversao-como-estratgia.

pdf > . Acesso em: 30 jan. 2011.

SILVA, Fernanda Mauricio. 0 Roda Viva e as

estratégias de construção de um debate público.

In: GOMES, Itania (Org.). Gêneros televisivos e

modos de endereçamento no telejornalismo.

Salvador: EDUFBA, 2010. p. 49-74.

TARDE, Gabriel. A opinião e a conversação. In: . A opinião e as massas. São Paulo:

Martins Fontes, 1992. p. 79-154.

WILLIAMS, Raymond. Marxismo e literatura.

Trad. Waltensir Dutra. Rio de Janeiro: Zahar

Editores, 1971. p. 179-184.

WYATT, Robert; KATZ, Elihu; KIM, Joohan.

Bridging the spheres: political and personal

conversation in public and private spaces.

Journal of Communication, v. 50, p. 71-92, winter, 2000. 
Conversation, TV

journalism, democracy and the rethoric of public participation

\section{La conversación, el periodismo de televisión, la democracia y la retórica de la participación pública}

\section{Resumen:}

Este artículo pretende discutir las formas de participación de los espectadores en las conversaciones de noticias de televisión, con el fin de problematizar su rol democrático. A través del análisis del programa Roda Viva (TV Cultura), se observa que las noticias de televisión utilizan tres niveles de inclusión de los programas públicos: completo, oculto y representativo. Se trata de demostrar, a partir de la contribución de los cultural studies, el periodismo televisivo que aún se presenta con relación autoritaria y excluyente a la inserción de las conversaciones del público en la escena.

\section{Palabras clave:}

Conversación. TV periodismo. Democracia. Participación. 


\section{Expediente}

A revista E-Compós é a publicação científica em formato eletrônico da Associação Nacional dos Programas de Pós-Graduação em Comunicação (Compós). Lançada em 2004, tem como principal finalidade difundir a produção acadêmica de pesquisadores da área de Comunicação, inseridos em instituições do Brasil e do exterior.

\section{E-COMPÓS I www.e-compos.org.br I E-ISSN 1808-2599}

Revista da Associação Nacional dos Programas de Pós-Graduação em Comunicação.

Brasília, v.14, n.1, jan/abr. 2011

A identificação das edições, a partir de 2008

passa a ser volume anual com três números.

\section{CONSELHO EDITORIAL}

Afonso Albuquerque, Universidade Federal Fluminense, Brasil Alberto Carlos Augusto Klein, Universidade Estadual de Londrina, Brasil Alex Fernando Teixeira Primo, Universidade Federal do Rio Grande do Sul, Brasil Ana Carolina Damboriarena Escosteguy, Pontifícia Universidade Católica do Rio Grande do Sul, Brasil

Ana Gruszynski, Universidade Federal do Rio Grande do Sul, Brasil Ana Silvia Lopes Davi Médola, Universidade Estadual Paulista, Brasil André Luiz Martins Lemos, Universidade Federal da Bahia, Brasil Ângela Freire Prysthon, Universidade Federal de Pernambuco, Brasil Angela Cristina Salgueiro Marques, Faculdade Cásper Líbero (São Paulo), Brasil Antônio Fausto Neto, Universidade do Vale do Rio dos Sinos, Brasil Antonio Carlos Hohlfeldt, Pontifícia Universidade Católica do Rio Grande do Sul, Brasil Antonio Roberto Chiachiri Filho, Faculdade Cásper Líbero, Brasil Arlindo Ribeiro Machado, Universidade de São Paulo, Brasil Arthur Autran Franco de Sá Neto, Universidade Federal de São Carlos, Brasil Benjamim Picado, Universidade Federal Fluminense, Brasil César Geraldo Guimarães, Universidade Federal de Minas Gerais, Brasil Cristiane Freitas Gutfreind, Pontifícia Universidade Católica do Rio Grande do Sul, Brasil Denilson Lopes, Universidade Federal do Rio de Janeiro, Brasil Denize Correa Araujo, Universidade Tuiuti do Paraná, Brasil Edilson Cazeloto, Universidade Paulista, Brasil Eduardo Peñuela Cañizal, Universidade Paulista, Brasil Eduardo Vicente, Universidade de São Paulo, Brasil Eneus Trindade, Universidade de São Paulo, Brasil Erick Felinto de Oliveira, Universidade do Estado do Rio de Janeiro, Brasil Florence Dravet, Universidade Católica de Brasília, Brasil Francisco Eduardo Menezes Martins, Universidade Tuiuti do Paraná, Brasil Gelson Santana, Universidade Anhembi/Morumbi, Brasil Gilson Vieira Monteiro, Universidade Federal do Amazonas, Brasil Gislene da Silva, Universidade Federal de Santa Catarina, Brasil Guillermo Orozco Gómez, Universidad de Guadalajara Gustavo Daudt Fischer, Universidade do Vale do Rio dos Sinos, Brasil Hector Ospina, Universidad de Manizales, Colômbia Herom Vargas, Universidade Municipal de São Caetano do Sul, Brasil leda Tucherman, Universidade Federal do Rio de Janeiro, Brasil Inês Vitorino, Universidade Federal do Ceará, Brasil Janice Caiafa, Universidade Federal do Rio de Janeiro, Brasil Jay David Bolter, Georgia Institute of Technology Jeder Silveira Janotti Junior, Universidade Federal de Pernambuco, Brasil João Freire Filho, Universidade Federal do Rio de Janeiro, Brasil
John DH Downing, University of Texas at Austin, Estados Unidos José Afonso da Silva Junior, Universidade Federal de Pernambuco, Brasil José Carlos Rodrigues, Pontifícia Universidade Católica do Rio de Janeiro, Brasil José Luiz Aidar Prado, Pontifícia Universidade Católica de São Paulo, Brasil José Luiz Warren Jardim Gomes Braga, Universidade do Vale do Rio dos Sinos, Brasil Juremir Machado da Silva, Pontifícia Universidade Católica do Rio Grande do Sul, Brasil Laan Mendes Barros, Universidade Metodista de São Paulo, Brasil Lance Strate, Fordham University, USA, Estados Unidos Lorraine Leu, University of Bristol, Grã-Bretanha Lucia Leão, Pontifícia Universidade Católica de São Paulo, Brasil Luciana Panke, Universidade Federal do Paraná, Brasil Luiz Claudio Martino, Universidade de Brasília, Brasil Malena Segura Contrera, Universidade Paulista, Brasil Márcio de Vasconcellos Serelle, Pontifícia Universidade Católica de Minas Gerais, Brasi Maria Aparecida Baccega, Universidade de São Paulo e Escola Superior de Propaganda e Marketing, Brasil

Maria das Graças Pinto Coelho, Universidade Federal do Rio Grande do Norte, Brasil Maria Immacolata Vassallo de Lopes, Universidade de São Paulo, Brasil Maria Luiza Martins de Mendonça, Universidade Federal de Goiás, Brasil Mauro de Souza Ventura, Universidade Estadual Paulista, Brasil Mauro Pereira Porto, Tulane University, Estados Unidos Nilda Aparecida Jacks, Universidade Federal do Rio Grande do Sul, Brasil Paulo Roberto Gibaldi Vaz, Universidade Federal do Rio de Janeiro, Brasil Potiguara Mendes Silveira Jr, Universidade Federal de Juiz de Fora, Brasil Renato Cordeiro Gomes, Pontifícia Universidade Católica do Rio de Janeiro, Brasil Robert K Logan, University of Toronto, Canadá

Ronaldo George Helal, Universidade do Estado do Rio de Janeiro, Brasil Rosana de Lima Soares, Universidade de São Paulo, Brasil Rose Melo Rocha, Escola Superior de Propaganda e Marketing, Brasil Rossana Reguillo, Instituto de Estudos Superiores do Ocidente, Mexico Rousiley Celi Moreira Maia, Universidade Federal de Minas Gerais, Brasil Sebastião Carlos de Morais Squirra, Universidade Metodista de São Paulo, Brasil Sebastião Guilherme Albano da Costa, Universidade Federal do Rio Grande do Norte, Brasil

Simone Maria Andrade Pereira de Sá, Universidade Federal Fluminense, Brasil Tiago Quiroga Fausto Neto, Universidade de Brasília, Brasil Suzete Venturelli, Universidade de Brasilia, Brasil

Valério Cruz Brittos, Universidade do Vale do Rio dos Sinos, Brasil Valerio Fuenzalida Fernández, Puc-Chile, Chile Veneza Mayora Ronsini, Universidade Federal de Santa Maria, Brasil Vera Regina Veiga França, Universidade Federal de Minas Gerais, Brasil

\section{COMISSÃO EDITORIAL}

Adriana Braga I Pontifícia Universidade Católica do Rio de Janeiro, Brasil Felipe Costa Trotta I Universidade Federal de Pernambuco, Brasil CONSULTORES AD HOC

Édison Gastaldo I Universidade Federal Rural do Rio de Janeiro, Brasil Gisela Grangeiro da Silva Castro, Escola Superior de Propaganda e Marketing, Brasil Helio Kuramoto, Instituto Brasileiro de Informação em Ciência e Tecnologia, Brasil Juliano Maurício de Carvalho, Universidade Estadual Paulista, Brasil Maria Helena Weber, Universidade Federal do Rio Grande do Sul, Brasi Paulo Carneiro da Cunha Filho, Universidade Federal de Pernambuco, Brasil Vera Regina Veiga França, Universidade Federal de Minas Gerais, Brasil EDIÇÃO DE TEXTO E RESUMOS I Susane Barros SECRETÁRIA EXECUTIVA I Juliana Depiné EDITORAÇÃo ELETRÔNICA I Roka Estúdio
COMPóS I www.compos.org.br

Associação Nacional dos Programas de Pós-Graduação em Comunicação

Presidente

Itania Maria Mota Gomes

Universidade Federal da Bahia, Brasil

itania@ufba.br

Vice-presidente

Julio Pinto

Pontifícia Universidade Católica de Minas Gerais, Brasil juliopinto@pucminas.br

Secretária-Geral

Ana Carolina Escosteguy

Pontifícia Universidade Católica do Rio Grande do Sul, Brasil carolad@pucrs.br 